\title{
PENGARUH TEKANAN DAN SUHU TERHADAP REJEKSI Gd-DTPA DAN Sm- DTPA DENGAN MENGGUNAKAN MEMBRAN NANOFILTRASI
}

\author{
Iman Rahayu, Rustaman, Anni Anggraeni, Atiek Rostika Noviyanti, Rubianto A. Lubis \\ Departemen Kimia, Fakultas Matematika dan Ilmu Pengetahuan Alam, Universitas Padjadjaran, J1. Raya \\ Bandung-Sumedang km 21, Jatinangor, Jawa Barat 45363, Indonesia, Telp/Fax 0227794391 \\ *Alamat Korespondensi: iman.rahayu@unpad.ac.id
}

\begin{abstract}
Abstrak: Saat ini telah banyak dilakukan penelitian mengenai pemisahan unsur tanah jarang karena peranannya penting dalam perkembangan teknologi. Pemisahan dan pemurnian unsur tanah jarang sangat sulit dilakukan karena unsur tanah jarang memiliki kemiripan sifat antara satu dengan yang lainnya.Oleh karena itu, perlu dilakukan pengembangan metode-metode pemisahan dan pemurnian unsur tanah jarang dari mineralmineralnya, salah satunya dengan membran nanofiltrasi dengan penambahan ligan dietilentriaminpentaasetat (DTPA).Penelitian ini bertujuan untuk memisahkan gadolinium(III) dan samarium(III) dengan menggunakan membran nanofiltrasi. Metode yang digunakan dalam penelitian adalah pembuatan larutan standar gadolinium(III) dan samarium(III), pembuatan larutan kompleks dan pemisahan dengan membran nanofiltrasi pada variasi tekanan 2-6 bar dan suhu $20-40^{\circ} \mathrm{C}$. Permeat hasil dari pemisahan kemudian dianalisis dengan menggunakan ICP-AES. Dari hasil penelitian ini diperoleh tekanan optimum yaitu 2 bar dengan menghasilkan rejeksi Gd-DTPA sebesar 97,52 \% dan Sm-DTPA sebesar 97,28 \%. Suhu optimum yang diperoleh yaitu $20^{\circ} \mathrm{C}$ dengan menghasilkan rejeksi Gd-DTPA sebesar 99,73\% dan Sm-DTPA sebesar 99,58\%.
\end{abstract}

Kata kunci: Gd-DTPA, Sm-DTPA, nanofiltrasi

\begin{abstract}
Nowadays has been done research on the separation of rare earths as an important role in the development of technology. The separation and purification of rare earths is very difficult, because of the rare earth elements have similar properties with each other. Therefore, it is necessary to develop methods of separation and purification of rare earths from minerals, one of them is nanofiltration membrane with the addition of ligand Diethylene triaminepentaacetat (DTPA). This study aims to separate gadolinium(III) and samarium(III) by using nanofiltration membranes. The method used in this research is the preparation of standard solution of gadolinium(III) and samarium(III), the preparation of complex solution and separation by nanofiltration membrane at 2-6 bar pressure variations and temperature of $20-40^{\circ} \mathrm{C}$. Permeate the result of the separation was analyzed using Inductively Coupled Plasma - Atomic Emission Spectrometry (ICP-AES). The results obtained optimum pressure at 2 bar to produce a rejection Gd-DTPA is $97.52 \%$ and Sm-DTPA is 97.28\%. The optimum temperature at $20^{\circ} \mathrm{C}$ to produce a rejection Gd-DTPA is $99.73 \%$ and Sm-DTPA is $99.58 \%$.
\end{abstract}

Keywords: Gd-DTPA, Sm-DTPA, nanofiltration

\section{PENDAHULUAN}

Indonesia termasuk negara yang kaya akan sumber daya alam, salah satu contohnya yaitu kekayaan unsur tanah jarang. Unsur tanah jarang umumnya terbentuk bersama-sama dengan unsur lainnya seperti tembaga, uranium, fosfat, emas, dan besi, sebagai mineral ikutan.Mineral ikutan tersebut pada saat penambangan dan pengolahan timah ditemukan sebagai produk sampingan.

Saat ini banyak dilakukan penelitian mengenai pemisahan unsur tanah jarang karena unsur tanah jarang memegang banyak peranan dalam perkembangan teknologi. Beberapa peranan unsur tanah jarang terdapat pada bidang teknik kimia, metalurgi, energi nuklir, superkonduktor suhu tinggi, dan katalisis (Sorin et al. 2005).

Unsur tanah jarang banyak ditemukan di alam dalam bentuk monasit dan senotim.Monasit mengandung unsur tanah jarang ringan, sedangkan senotim mengandung unsur tanah jarang berat (Ni et al. 1995). Dari mineral monasit tersebut dapat diperoleh unsur tanah jarang dalam bentuk oksida dan murni apabila diolah dengan metode yang tepat. Pemanfaatan mineral monasit ini sangat tinggi dibanding mineral unsur tanah jarang lainnya dikarenakan mengandung unsur gadolinium (Gd) dan samarium (Sm). Gadolinium dapat dimanfaatkan sebagai agen pengontras pada alat pencitra resonansi magnetik (MRI), telah teruji secara klinis pada tahun 1988 oleh Weinmann. Sedangkan samarium biasa digunakan sebagai bahan pembuat magnet dan laser.

Teknologi membran telah banyak digunakan terutama dalam proses pemisahan karena prosesnya yang lebih cepat, biaya murah, efisiensi dalam menggunakan energi dan tidak terjadi perubahan fasa dalam larutan yang dipisahkan. Saat ini proses nanofiltrasi telah digunakan sebagai salah satu proses pemisahan partikel dalam larutan. Nanofiltrasi merupakan salah satu teknologi membran yang memiliki molecular weight cut-off (MWCO) antara 200 sampai 600 Da, sehingga dapat memisahkan partikel berukuran kecil dan partikel ionik (Mulder 
1996; Chitry et al. 2001). Mekanisme pemisahan nanofiltrasi berdasarkan molecular weight cut-off (MWCO) yang berhubungan dengan ukuran pori pada membran dan berdasarkan perbedaan muatan antara membran dengan larutan (Sorin et al. 2004).

Teknologi membran nanofiltrasi ini dapat digunakan untuk pemisahan unsur tanah jarang melalui tahap kompleksasi dengan ligan. Seperti yang telah dilakukan oleh Chitry et al. (1999) dalam pemisahan lantanida (III) menggunakan nanofiltrasikompleksasi dalam medium cair, memberikan hasil 95\% gadolinium(III) yang terpisah. Sorin et al. (2004) dalam pemisahan lantanida(III)/aktinida(III) dengan nanofiltrasi-kompleksasi, memberikan hasil gadolinium kompleks yang terejeksi sebesar $99 \%$. Beberapa faktor yang mempengaruhi hasil rejeksi menggunakan nanofiltrasi seperti tekanan, dan suhu.

Pada penelitian ini gadolinium(III) dan samarium(III) membentuk kompleks dengan ligan dietilentriaminpentaasetat (DTPA) yang nantinya akan terejeksi oleh membran nanofiltrasi dan diamati pengaruh variasi tekanan pada 2-6 bar dan variasi suhu pada $20-40^{\circ} \mathrm{C}$.

\section{BAHAN DAN METODE \\ Bahan}

Akua Milli-Q (Laboratorium sentral, Universitas Padjadjaran), asam klorida p.a., asam nitrat p.a., natrium hidroksida p.a., asam asetat p.a., membran nanofiltrasi Dow FilmTec TW30-1812-50 yang terbuat dari material poliamida dengan ukuran pori $0,1 \mathrm{~nm}$ dan luas permukaan $150 \mathrm{~cm}^{2}$, gadolinium oksida (Sigma Aldrich), samarium oksida (Sigma Aldrich), dan dietilen triamin pentaasetat (DTPA) (Sigma Aldrich).

\section{Metode}

Pertama, pembuatan larutan kompleks Gd-DTPA dan Sm-DTPA. Sebanyak $100 \mathrm{~mL}$ larutan gadolinium 3145 ppm, $100 \mathrm{~mL}$ larutan samarium 3007 ppm, dan 100 mL larutan DTPA 7867 ppm dimasukkan ke dalam gelas kimia dan diatur $\mathrm{pH}$-nya dengan penambahan larutan natrium hidroksida $2 \mathrm{M}$ atau larutan asam klorida 0,5 M sampai $\mathrm{pH} 7$, kemudian diaduk sampai homogen. Setelah itu larutan dimasukkan ke dalam gelas kaca dan ditambahkan akua Milli-Q sampai volume $4 \mathrm{~L}$.

Larutan kompleks Gd-DTPA dan Sm-DTPA yang bertindak sebagai larutan umpan dialirkan ke dalam membran nanofiltrasi, kemudian diatur tekanannya pada variasi $2-6$ bar dan suhu pada $20-40^{\circ} \mathrm{C}$. Proses pemisahan dijalankan dengan sistem cross-flow selama 15 menit. Setelah kondisi stabil kemudian permeat ditampung dalam gelas kimia.

Permeat yang telah ditampung kemudian diukur nilai fluks dan rejeksinya. Fluks permeat dihitung dengan mengukur volume permeat yang melewati membran per satuan luas permukaan membran dikalikan waktu untuk masing-masing kondisi (tekanan dan suhu pemisahan), sesuai dengan persamaan:

$$
J v=\frac{V}{A \cdot t}
$$

Rejeksi dihitung dengan mengukur konsentrasi umpan dan permeat dengan menggunakan Inductively Coupled Plasma - Atomic Emission Spectrometry (ICP-AES) kemudian dihitung dengan menggunakan persamaan:

$$
R=\left(1-\frac{C p}{C r}\right) x 100 \%
$$

\section{HASIL DAN PEMBAHASAN \\ Pengaruh Tekanan Terhadap Fluks Permeat dan Rejeksi}

Pengaruh tekanan terhadap fluks permeat dan rejeksi Gd-DTPA dan Sm-DTPA pada membran dapat dilihat pada Gambar 1. Semakin tinggi tekanan maka fluks larutan akan semakin besar. Hal ini disebabkan karena adanya pengaruh gaya dorong tekanan maka molekul-molekul dalam larutan akan semakin banyak melewati membran.

Tekanan juga berpengaruh terhadap rejeksi, semakin besar tekanan maka rejeksi Gd-DTPA dan Sm-DTPA semakin meningkat. Hal ini disebabkan karena dengan meningkatnya tekanan akan meningkatkan laju alir pada membran sehingga umpan yang mengandung Gd-DTPA dan Sm-DTPA akan banyak menumpuk pada permukaan atau dapat terjadi polarisasi konsentrasi. Sehingga gadolinium(III) dan samarium(III) yang melewati membran akan semakin sedikit. Pada Gambar 1 dapat dilihat walaupun rejeksinya meningkat tetapi fluks permeat pun meningkat. Hal ini mengindikasikan jika yang melewati membran merupakan molekul air karena semakin tinggi tekanan, fluks permeat semakin tinggi tetapi rejeksi nya pun tinggi.

Pada Gambar 1 dapat dilihat bahwa rejeksi terbesar terjadi pada tekanan 6 bar dimana rejeksi Sm-DTPA sebesar 99,38\% dan rejeksi Gd-DTPA sebesar 99,43\%, namun hal ini dinilai kurang efektif dalam pemisahan samarium dan gadolinium karena memiliki rejeksi yang tidak berbeda jauh. Pada penelitian ini pemisahan optimumnya terjadi pada tekanan 2 bar dimana rejeksi Sm-DTPA sebesar 97,28 \% dan rejeksi Gd-DTPA sebesar 97,52\%.Pada tekanan 2 bar memiliki selisih yang sedikit lebih jauh dibandingkan dengan tekanan 3-6 bar. Hasil penelitian ini menunjukkan jika gadolinium(III) dan samarium(III) hampir sama banyak berikatan dengan ligan DTPA. Oleh karena itu, diperlukan suatu ligan spesifik yang bisa mengikat salah satu unsur sehingga dapat diperoleh salah satu kompleks yang lebih banyak. 


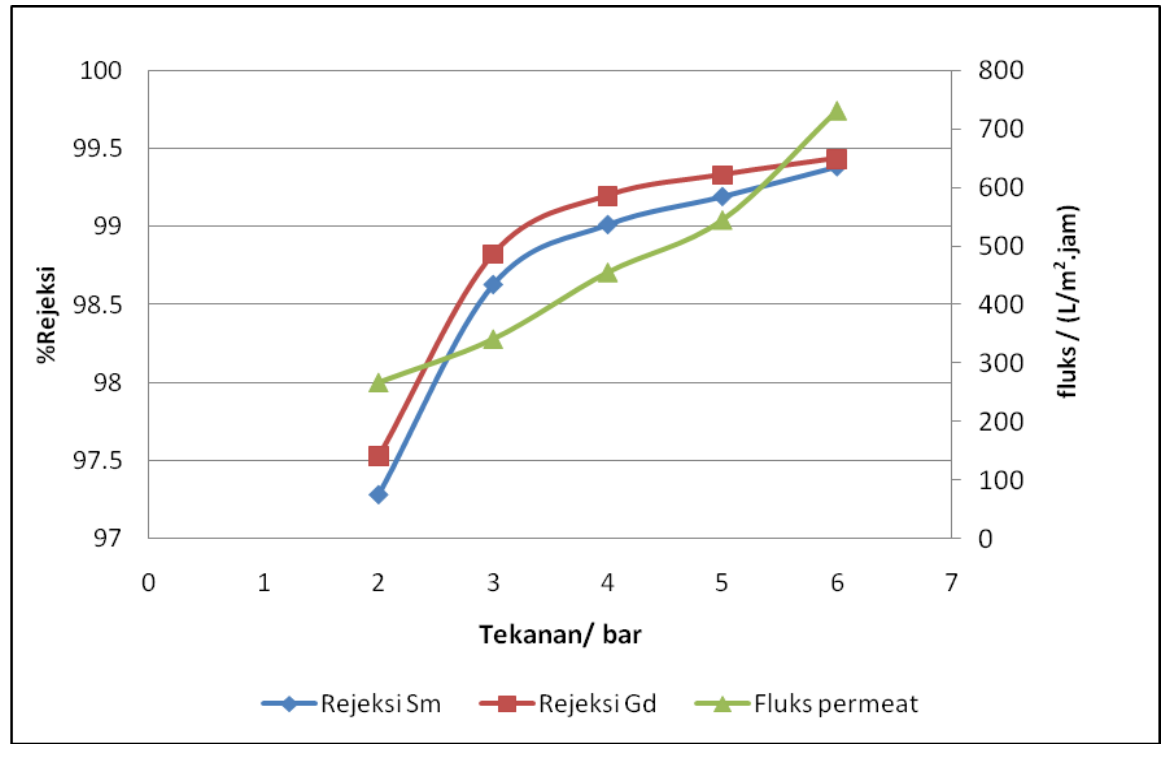

Gambar 1. Pengaruh tekanan terhadap fluks permeat dan rejeksi

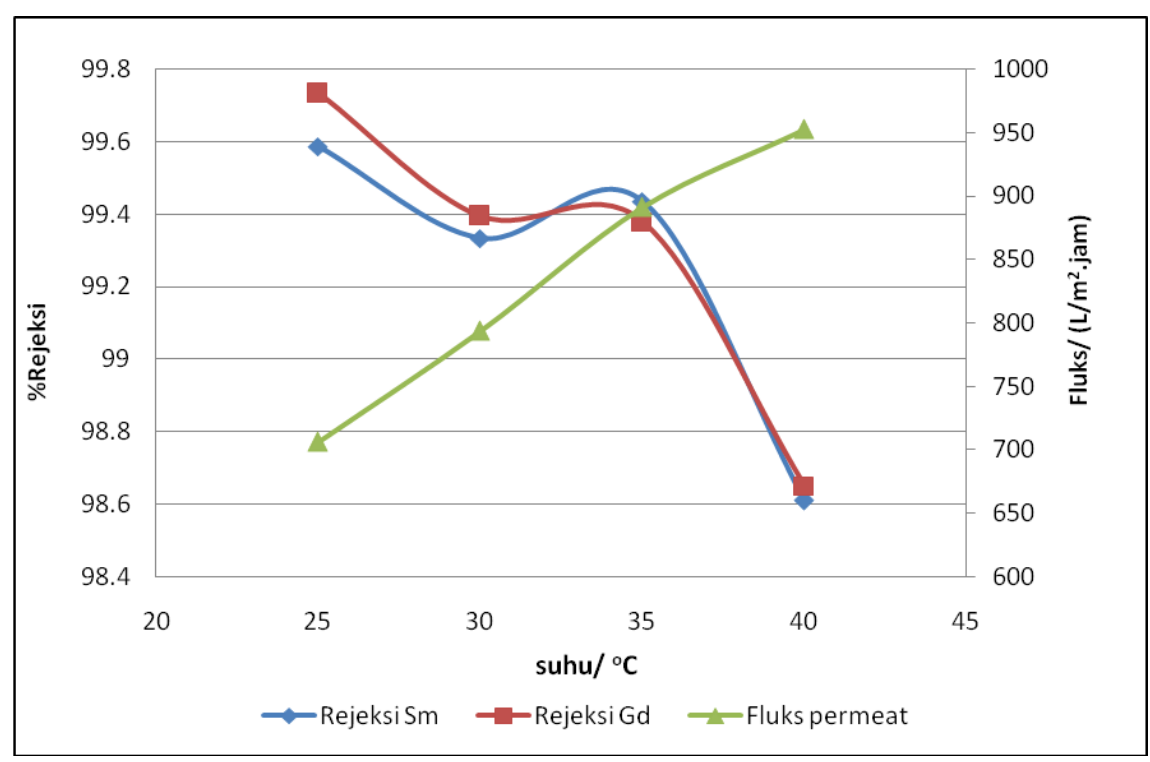

Gambar 2. Pengaruh suhu terhadap fluks permeat

\section{Pengaruh Suhu Terhadap Fluks Permeat dan Rejeksi}

Pengaruh suhu terhadap fluks permeat larutan GdDTPA dan Sm-DTPA pada membran dapat dilihat pada Gambar 2. Semakin tinggi suhu yang digunakan maka akan semakin tinggi fluks permeat yang dihasilkan. Hal ini disebabkan karena semakin tinggi suhu yang digunakan maka akan menyebabkan semakin besar ukuran pori membran. Hasil ini sama seperti yang telah dilakukan oleh Sorin et al. (2005).

Suhu juga berpengaruh terhadap rejeksi GdDTPA dan Sm-DTPA, semakin besar suhu maka akan semakin kecil rejeksi dikarenakan ukuran pori yang membesar sehingga banyak ion-ion yang melewati membran. Selain itu peningkatan suhu menyebabkan penurunan viskositas larutan.
Penurunan viskositas larutan berpengaruh tehadap jarak antar partikel dalam larutan akan semakin renggang, sehingga akan menurunkan rejeksi (Sorin et al. 2005).

Rejeksi yang di hasilkan optimum pada suhu $20^{\circ} \mathrm{C}$ dengan menghasilkan rejeksi Gd-DTPA sebesar 99,73\% dan rejeksi Sm-DTPA sebesar 99,58\%. Pada suhu $20^{\circ} \mathrm{C}$ dinilai lebih efektif untuk memisahkan gadolinium dan samarium karena memiliki selisih yang sedikit lebih jauh dibandingkan pemisahan pada suhu $25-40^{\circ} \mathrm{C}$.

\section{KESIMPULAN}

1. Semakin tinggi tekanan yang diberikan pada membran, maka rejeksi Gd-DTPA dan SmDTPA semakin tinggi. 
2. Semakin tinggi suhu yang diberikan pada membran, maka rejeksi Gd-DTPA dan SmDTPA semakin kecil.

3. Suhu optimum dilakukan pada $20^{\circ} \mathrm{C}$ dan menghasilkan rejeksi Gd-DTPA dan Sm-DTPA masing-masing sebesar $99,73 \%$ dan $99,58 \%$.

4. Tekanan optimumdilakukan pada 2 bar dan menghasilkan rejeksi Gd-DTPA dan Sm-DTPA masing-masing sebesar $97,52 \%$ dan $97,28 \%$.

\section{DAFTAR PUSTAKA}

Chitry, F., Garcia, I.R, Nicod, L., Gass, J.L, Madic, C. \& Lemaire, M. (1999). Separation of gadolinium(III) and lanthanum(III) by nanofiltration-complexation in aqueous medium. Journal of Radioanalytical and Nuclear Chemistry. 240(3): 931-934.

Ni, Y., Hughes, J.M. \& Mariano, A.N. (1995). Crystal chemistry of the monazite and xenotime structures. American Mineralogist. 80(1): 2126.
Mulder, N. (1996). Basic Principles of Membrane Technology. London: Kluwer Academic Publisher.

Murthy, Z.V.P. \& Choudhary, A. (2011). Separation of cerium from feed solution by nanofiltration. Desalination. 279(1): 428-432.

Murthy, Z.V.P. \& Choudhary, A. (2011). Application of nanofiltration to treat rare earth element (neodymium) containing water. Journal of Rare Earths. 29(10) 974-978.

Sorin, A., Favre-Réguillon, A., Pellet-Rostaing, S., Sbaï, M., Szymczyk, A., Fievet, P. \& Lemaire, M. (2005). Rejection of Gd (III) by nanofiltration assisted by complexation on charged organic membrane: Influences of $\mathrm{pH}$, pressure, flux, ionic strength and temperature. Journal of Membrane Science. 267(1): 41-49.

Sorin, A., Pellet-Rostaing, S., Favre Reguillon, A., Bernier, G., Adnet, J.M. \& Lemaire, M. (2004). Lanthanides (III)/Actinides (III) separation by nano-filtration-complexation. In Atalante 2004 conference: Advances for future nuclear fuel cycles. Nimes (France), 21-24 June 2004. 